\title{
OPEN Safety of switching between rituximab biosimilars in onco-hematology
}

\author{
Silvana A. M. Urru ${ }^{1,2 \bowtie}$, Stefania Spila Alegiani ${ }^{3}$, Anna Guella ${ }^{4}$, Giuseppe Traversa ${ }^{3}$ \& \\ Annalisa Campomori ${ }^{1}$
}

Comparable clinical efficacy and safety of the reference rituximab (MABTHERA) and its biosimilars has been established in randomized trials. However, safety concerns are often raised when switching from reference to biosimilar products and between different biosimilars. In this prospective observational study we aimed at evaluating the safety of switching between reference and biosimilar rituximab (TRUXIMA and RIXATHON) at Trento General Hospital (Italy). All patients $(n=83)$ with Non Hodgkin's Lymphoma (NHL, $n=72$ ) and Chronic Lymphocytic Leukemia $(C L L, n=11)$ who received rituximab between March 2018 and March 2019 were asked to take part in the study. In 2017 and 2018 two tenders were carried out and two different biosimilars became available in the hospital, these were used sequentially. Thus, patients with or without previous treatments with the originator rituximab either received a biosimilar or were switched between different biosimilars. The incidence of adverse events in these groups of patients is described. The study population received 465 rituximab infusions and all received biosimilars. Fifty patients $(60 \%)$ experienced at least one switch between different biosimilars or between rituximab originator and biosimilar, whereas $33(40 \%)$ received one of the two biosimilars and one patient received reference rituximab. Adverse events $(n=146)$ were reported in 71 patients $(84.5 \%)$. Treatment-related grade 3-4 events were reported in 5 patients $(5.9 \%)$, whereas grade 1 rituximab related infusion events were observed in 6 patients (7.1\%). No safety signal emerged in association with the use of a specific biosimilar nor with the practice of switching. Adverse events were similar, in terms of seriousness and frequency, to those described in the literature, providing further support to the clinical safety of rituximab biosimilars.

Biosimilars are approved on the basis of a comprehensive comparability exercise aimed at establishing the similarity to the reference medicinal products in terms of quality, biological activity, safety and efficacy ${ }^{1}$.

The first biosimilars introduced in Europe in 2006, were biosimilar somatropins ${ }^{2}$. Until recently, only biosimilars of these lower molecular-weight biologics were available. This changed in September 2013 when the European Medicines Agency (EMA) recommended the granting of marketing authorization for the first time for two biosimilar versions of the monoclonal antibody $(\mathrm{mAb})$ infliximab ${ }^{3}$.

As of 1 st January 2021, there are 58 authorized products in the EU and 29 in the USA ${ }^{4}$. Existing data on switching for selected biosimilars have been generated from several studies ${ }^{5-7}$. In more than 10 years of clinical experience, no substantial clinical and safety differences have been detected ${ }^{8}$. However, especially for newly marketed biosimilars, concerns are raised with respect to the practice of switching in patients already treated with a specific biologic product (either reference or biosimilar) ${ }^{9}$.

Differently for the FDA, the EMA does not make a distinction between biosimilars and interchangeable products and advice to prescribers fall under the responsibility of member states ${ }^{10}$.

In Europe, biosimilars have become a reality, with some biosimilars achieving market share of $>90 \%$, while in the USA, the uptake of biosimilars has been modest thus far ${ }^{11}$.

The first biosimilar rituximab was approved in $2017^{9}$. The equivalence between reference rituximab (MABTHERA) and its biosimilars-in terms of pharmacokinetics, pharmacodynamics, efficacy, safety and immunogenicity-has been demonstrated in randomized, double-blind, controlled trials ${ }^{12-15}$.

\footnotetext{
${ }^{1}$ Hospital Pharmacy Unit, Trento General Hospital, Autonomous Province of Trento, Trento, Italy. ${ }^{2}$ School of Hospital Pharmacy, University of Sassari, Sassari, Italy. ${ }^{3}$ Pharmacoepidemiology Unit, National Center for Drug Research and Evaluation, Italian National Institute of Health, Rome, Italy. ${ }^{4}$ Hematology Unit, Trento General Hospital, Autonomous Province of Trento, Trento, Italy. ${ }^{\circledR}$ email: silvanaurru@gmail.com
} 
After a careful review of the scientific evidence on rituximab, hematologists and pharmacists working at Trento General Hospital agreed that reference and biosimilar products could be used interchangeably in all patients, both naïve and experienced ones. Consequently, in 2017 and 2018 two tenders were carried out and two different biosimilars became available in the hospital: TRUXIMA (Mundipharma) in the first year and RIXATHON (Sandoz) in the second one. It was also agreed to conduct a prospective observational study specifically focusing on safety to build patient and physician confidence.

The aim of the study was to document any adverse event (AE) reported in association with the use of biosimilar rituximab and with the practice of switching between different products in patients with Non Hodgkin's Lymphoma (NHL) and Chronic Lymphocytic Leukemia (CLL).

\section{Methods}

The study was conducted in accordance with ethical principles derived from guidelines that included the Declaration of Helsinki ${ }^{16}$, as well as following all relevant local requirements. The Ethics Committee of the Health Trust of the Autonomous Province of Trento approved the study protocol (2018/n.4586). Informed consent was secured from all subjects in this study. Patients were treated according to the usual practice and no additional procedure was carried out. Each patient was informed about the objectives of the study and provided written informed consent to collect and analyze data for research purposes.

The study population consisted of adult patients with NHL and CLL, consecutively admitted into the Hematology Unit of the Trento General Hospital from March 10th 2018 to March 10th 2019, whose therapy included rituximab administration. Patients were followed up until the first of the following dates: last follow up visit, death, end of study (30 September 2019).

Baseline characteristics were ascertained at the time of the first infusion of rituximab (dosed at $375 \mathrm{mg} / \mathrm{m}^{2}$ as part of standard treatment), during the study period. Data were collected on patient characteristics (i.e., diagnosis, age, body surface area, performance status), previous treatment and concomitant medications, premedications, rituximab indications, dosage and administration.

During the study period, patients may have received: (a) either a biosimilar or the reference product (noswitch group); (b) two biosimilar products (switch during the study period); (c) a rituximab formulation (reference or biosimilar) that was different from the one received before the study period (anamnestic switch).

Adverse events (AEs) of interest consisted of Infusion Related Reactions (IRR) (i.e., type of reaction, treatment of reaction, duration of interruption of infusion) and other adverse events occurring between different infusions, regardless of their severity (grade 1-4). Safety follow-up took place at every administration of rituximab; information on adverse events occurring at home was obtained at every clinical access (at least once per month). The causality assessment for all drug-event couples was made by the attending physicians using the Naranjo algorithm ${ }^{17}$.

NHL and CLL disease activity was assessed according to the local clinical practice routine, after the third cycle (week 9) and at the end-of-treatment visit, and was grouped as overall response rate, complete response, partial response, stable disease, progressive disease ${ }^{18,19}$.

Performance status was assessed by clinicians using the Eastern Cooperative Oncologic Group Scale (ECOG) scale ${ }^{20}$.

We described the characteristics of patients included in the study using counts with percentages and median with interquartile range (IQR) for categorical and continuous variables, respectively. The incidence of AEs among patients with "no-switch", "switch during the study period" and "anamnestic switch" was analysed through a Chi-square test for categorical variables. Both the number of patients and the number of infusions were used as denominator of the events of interest. The study population represented the experience of a single hospital and no formal sample size calculation was carried out.

\section{Results and discussion}

Eighty-three patients ( 37 women and 46 men) affected by NHL $(n=72)$ and CLL $(n=11)$ were included in the study (Table 1). Patients had a median age of 71 years (interquartile range-IQR 63-79 years) and more than $20 \%$ had a performance status $\geq 3$. The median follow-up of the patients was 10.5 months (IQR 7-14 months).

During the study period the patient population received 465 infusions of intravenous rituximab (163 TRUXIMA, and 302 RIXATHON). The median dosage received was $652 \mathrm{mg}$ (range 500-900 mg). The median number of infusions per patient was 5.6 (range 1-8 infusions). All patients $(n=83)$ received biosimilars. Among non-switchers, 33 patients $(40 \%)$ received a biosimilar formulation. At least one switch was experienced by the remaining 50 patients (60\%): 26 (31\%) during the study period and 24 (29\%) before the study period (anamnestic switch).

Adverse events $(n=146)$ were reported in 71 patients $(85.5 \%)$. Fifty-five $(66.3 \%)$ and $10(12.0 \%)$ patients had respectively neutropenia or anemia of grade 1-2. Treatment-related grade 3-4 AEs were reported in five patients (6.0\%): neutropenia in two patients, and febrile neutropenia, thrombocytopenia, liver toxicity, in one patient each. Six patients experienced rituximab related adverse events of grade 1 , which is consistent with the scientific literature (Table 2$)^{21}$.

The incidence of AEs was similar in patients who received one or two biosimilar formulations, both for any events $(32 / 33$ patients in the no switch group vs $25 / 26$ patients with a switch during the study period, $\mathrm{p}=0.86)$ and for events of grade $3-4(2 / 33$ vs $1 / 26 ; p=0.70)$.

The proportion of AEs was lower in patients who were receiving a rituximab formulation (one biosimilar or the other) that was different from the one before the study period (14 out of 24 patients, $58 \%$; 2 events of grade 3-4) (data not shown). 


\begin{tabular}{|c|c|}
\hline N. of patients & 83 \\
\hline Female [n (\%)] & $37(44.0 \%)$ \\
\hline $\mathrm{BSA}\left(\mathrm{m}^{2}\right)[$ median $(\mathrm{IQR})]$ & $1.8(1.7-1.9)$ \\
\hline Age at diagnosis (years) [median (IQR)] & $68(62-78)$ \\
\hline Age at baseline (years) [median (IQR)] & $71(63-79)$ \\
\hline \multicolumn{2}{|l|}{ Diagnosis [n (\%)] } \\
\hline NHL & $72(86.9 \%)$ \\
\hline \multicolumn{2}{|l|}{ Indolent NHL } \\
\hline Follicular lymphoma & $19(23.8 \%)$ \\
\hline Extranodal marginal zone (MALT) & $1(1.2 \%)$ \\
\hline \multicolumn{2}{|l|}{ Aggressive NHL } \\
\hline Diffuse large B-cell CD20 positive & $51(60.7 \%)$ \\
\hline Mantle cell lymphoma & $1(1.2 \%)$ \\
\hline CLL & $11(13.1 \%)$ \\
\hline \multicolumn{2}{|l|}{ Performance status [n (\%)] } \\
\hline 0 & $4(4.8 \%)$ \\
\hline 1 & $27(32.1 \%)$ \\
\hline 2 & $33(39.9 \%)$ \\
\hline$\geq 3$ & $17(20.2 \%)$ \\
\hline NA & $2(3.6 \%)$ \\
\hline \multicolumn{2}{|c|}{ Cycles of rituximab, total cycles n. 465 [n (\%)] } \\
\hline Biosimilar-TRUXIMA & $163(34.9 \%)$ \\
\hline Biosimilar-RIXATHON & $302(63.6 \%)$ \\
\hline \multicolumn{2}{|l|}{ Switch, total patients n. 83 [n (\%)] } \\
\hline No switch & $33(40.5 \%)$ \\
\hline Switch during the study period & $26(31.9 \%)$ \\
\hline Anamnestic switch & $24(28.6 \%)$ \\
\hline \multicolumn{2}{|l|}{ Response, NHL [n (\%)] } \\
\hline Complete response & $60(83.6 \%)$ \\
\hline Partial response & $7(9.6 \%)$ \\
\hline Progressive disease & $3(4.1 \%)$ \\
\hline Not evaluated (ongoing treatment) & $2(2.7 \%)$ \\
\hline \multicolumn{2}{|l|}{ Response, CLL [n (\%)] } \\
\hline Complete response & $2(18.2 \%)$ \\
\hline Partial response & $2(18.2 \%)$ \\
\hline Progressive disease & $2(18.2 \%)$ \\
\hline Stable disease & $2(18.2 \%)$ \\
\hline Not evaluated (ongoing treatment) & $3(27.2 \%)$ \\
\hline
\end{tabular}

Table 1. Characteristics of patients. $n$ number, $B S A$ body surface area, IQR inter quartile range, NHL Non Hodgkin's Lymphoma, CLL chronic lymphocytic leukemia, NA not available.

After a median follow-up of 10 months, adverse events reported were similar in terms of seriousness and frequency, regardless of rituximab formulation and switching. The incidence of events was lower only in the group of prevalent patients who had been already treated in the past with a different rituximab formulation (anamnestic switching).

To our knowledge, this is the first real-life cohort study assessing the safety of switching between different rituximab formulations (biosimilars and originator) in NHL and CLL patients.

Although some open-label studies have shown an increased number of withdrawals or AEs following a switch, these outcomes were less frequently observed in randomized studies ${ }^{9,21}$ suggesting the potential occurrence of a "nocebo" effect resulting from negative expectations toward the biosimilar ${ }^{22}$.

The results of this study support the position that switching between biosimilars, or from reference rituximab to its biosimilars, as part of routine clinical practice in NHL and CLL patients, has the same safety profile expected in patients continuously treated with reference rituximab. Data from post-marketing studies and real-world experience are needed to provide additional information to supplement the strong evidence already obtained on biosimilars from RCTs.

The increasing availability of biosimilars has led to significant healthcare savings and provided greater patient access to high cost therapeutics ${ }^{23}$. However, the cost-saving potential depends on various factors, such as the price of the reference product and the competition market ${ }^{24}$. 


\begin{tabular}{|c|c|c|c|}
\hline \multirow[b]{2}{*}{ Adverse events } & Any grade & Grade 3-4 & $\begin{array}{l}\text { Rituximab related } \mathrm{AE}^{\mathrm{b}} \\
\text { Grade } 1-2\end{array}$ \\
\hline & n (\%) & n (\%) & n (\%) \\
\hline \multicolumn{4}{|l|}{ Hematologic } \\
\hline Neutropenia & $57(68.7)$ & $2(2.4)$ & - \\
\hline Anemia & $10(12.0)$ & - & - \\
\hline Febrile Neutropenia & $2(2.4)$ & $1(1.2)$ & - \\
\hline Thrombocytopenia & $2(2.4)$ & $1(1.2)$ & - \\
\hline \multicolumn{4}{|l|}{ Non hematologic } \\
\hline Fever & $13(15.7)$ & - & $2(2.4)$ \\
\hline Tingling of the hands or feet & $7(8.4)$ & - & - \\
\hline Rash & $6(7.2)$ & - & - \\
\hline Urinary tract infection & $5(6.0)$ & - & - \\
\hline Nause & $4(4.8)$ & - & - \\
\hline Constipation & $4(4.8)$ & - & - \\
\hline Cough & $2(2.4)$ & - & - \\
\hline Stuffy nose & $2(2.4)$ & - & $2(2.4)$ \\
\hline Liver toxicity & $1(1.2)$ & $1(1.2)$ & - \\
\hline Throat itching & $1(1.2)$ & - & $1(1.2)$ \\
\hline Back pain & $1(1.2)$ & - & $1(1.2)$ \\
\hline Dyspnea & $1(1.2)$ & - & $1(1.2)$ \\
\hline Tremors & $1(1.2)$ & - & $1(1.2)$ \\
\hline Headache & $1(1.2)$ & - & $1(1.2)$ \\
\hline Other & $26(31.3)$ & - & - \\
\hline
\end{tabular}

Table 2. Hematologic and non-hematologic adverse events registered during the study period ${ }^{\text {a }}$ (March 2018March 2019). $N$ number. ${ }^{a}$ Events experienced by at least two patients, or grade 3-4, or causally related to

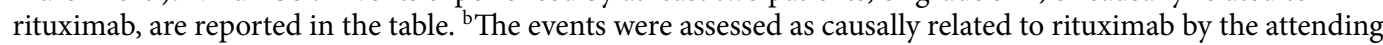
clinicians.

A cost-analysis study conducted in Europe, predicted that switching to a rituximab biosimilar would save $€ 56.82$ million over a year ${ }^{25}$.

In the setting of our hematology unit of a general hospital, this shared approach has increased clinicians and patients confidence in biosimilars with respect to safety, generating at the same time a $45 \%$ reduction in the price of rituximab (around 400,000 euros savings in one year).

\section{Data availability}

The data that support the findings of this study are available on request from the corresponding author [S.U.]. The data are not publicly available because they contain information that could compromise research participant privacy/consent.

Received: 16 April 2020; Accepted: 25 February 2021

Published online: 16 March 2021

\section{References}

1. Pasina, L., Casadei, G. \& Nobili, A. Biological agents and biosimilars: Essential information for the internist. Eur. J. Intern. Med. 33, 28-35 (2016)

2. Omnitrope, European Public Assessment Report, 12 April 2006. https://www.ema.europa.eu/en/documents/product-informatio n/omnitrope-epar-product-information_en.pdf. Accessed March 1, 2020.

3. European Medicines Agency (2013) European public assessment reports: Biosimilars. https://www.ema.europa.eu/en/documents/ press-release/european-medicines-agency-recommends-approval-first-two-monoclonal-antibody-biosimilars_en.pdf.

4. Food and Drug Administration. Purple book: Lists of licensed biological products with reference product exclusivity and biosimilarity or interchangeability evaluations. https://purplebooksearch.fda.gov/. Accessed January 28th, 2021.

5. Strik, A. S. et al. Serum concentrations after switching from originator infliximab to the biosimilar CT-P13 in patients with quiescent inflammatory bowel disease (SECURE): An open-label, multicentre, phase 4 non-inferiority trial. Lancet Gastroenterol. Hepatol. 3(6), 404-412 (2018).

6. Yoo, D. H. et al. Efficacy and safety of CT-P13 (biosimilar infliximab) in patients with rheumatoid arthritis: Comparison between switching from reference infliximab to CT-P13 and continuing CT-P13 in the PLANETRA extension study. Ann. Rheum. Dis. 76(2), 355-363 (2017).

7. Goll, G. L. et al. Long-term efficacy and safety of biosimilar infliximab (CT-P13) after switching from originator infliximab: Openlabel extension of the NOR-SWITCH trial. J. Intern. Med. 285(6), 653-669 (2019).

8. Biosimilars Medicines Group, A Medicines for Europe sector group. Docket submission and presentaton to the Oncologic Drugs Advisory Committee meeting of 13 July 2017. [commentary]. https://www.regulations.gov/document?D=FDA-2017-N-2732-0006.

9. Moots, R. et al. Switching between reference biologics and biosimilars for the treatment of rheumatology, gastroenterology, and dermatology inflammatory conditions: Considerations for the clinician. Curr. Rheumatol. Rep. 19(6), 37 (2017). 
10. Ebbers, H. C. \& Schellekens, H. Are we ready to close the discussion on the interchangeability of biosimilars?. Drug Discov. Today 24(10), 1963-1967 (2019).

11. EO'Callaghan, J., Barry, S. P. \& Bermingham, M. Regulation of biosimilar medicines and current perspectives on interchangeability and policy. Eur. J. Clin. Pharmacol. 75, 1-11 (2019).

12. Smolen, J. S. et al. A randomised, double-blind trial to demonstrate bioequivalence of GP2013 and reference rituximab combined with methotrexate in patients with active rheumatoid arthritis. Ann. Rheum. Dis. 76(9), 1598-1602 (2017).

13. Park, W. et al. Comparison of biosimilar CT-P10 and innovator rituximab in patients with rheumatoid arthritis: A randomized controlled Phase 3 trial. MAbs 10(6), 934-943 (2018).

14. Jurczak, W. et al. Rituximab biosimilar and reference rituximab in patients with previously untreated advanced follicular lymphoma (ASSIST-FL): Primary results from a confirmatory phase 3, double-blind, randomised, controlled study. Lancet Haematol. 4(8), e350-e361 (2017).

15. Ogura, M. et al. Efficacy, pharmacokinetics, and safety of the biosimilar CT-P10 in comparison with rituximab in patients with previously untreated low-tumour-burden follicular lymphoma: A randomised, double-blind, parallel-group, phase 3 trial. Lancet Haematol. 5(11), e543-e553 (2018).

16. World Medical Association. World Medical Association Declaration of Helsinki: Ethical principles for medical research involving human subjects. JAMA 310, 2191-2194 (2013).

17. Naranjo, C. A. et al. A method for estimating the probability of adverse drug reactions. Clin. Pharmacol. Ther. 30, 239-245 (1981).

18. Cheson, B. D. et al. Revised response criteria for malignant lymphoma. J. Clin. Oncol. 25(5), 579-586 (2007).

19. Hallek, M. et al. Guidelines for the diagnosis and treatment of chronic lymphocytic leukemia: A report from the International Workshop on Chronic Lymphocytic Leukemia updating the National Cancer Institute-Working Group 1996 guidelines. Blood 111(12), 5446-5456 (2008)

20. Oken, M. M. et al. Toxicity and response criteria of the Eastern Cooperative Oncology Group. Am. J. Clin. Oncol. 5(6), 649-655 (1982).

21. Jørgensen, K. K. et al. Switching from originator infliximab to biosimilar CT-P13 compared with maintained treatment with originator infliximab (NOR-SWITCH): A 52-week, randomised, double-blind, non-inferiority trial. Lancet 389(10086), 2304-2316 (2017).

22. Glintborg, B. et al. A nationwide non-medical switch from originator infliximab to biosimilar CT-P13 in 802 patients with inflammatory arthritis: 1-year clinical outcomes from the DANBIO registry. Ann. Rheum. Dis. 76(8), 1426-1431 (2017).

23. IMS Health. The impact of biosimilar competition in Europe. (2019). https://ec.europa.eu/docsroom/documents/38043.

24. Chopra, R. \& Lopes, G. Improving access to cancer treatments: The role of biosimilars. J. Glob. Oncol. 3, 596-610 (2017).

25. Janjigian, Y. Y., Bissig, M., Curigliano, G., Coppola, J. \& Latymer, M. Talking to patients about biosimilars. Future Oncol. 14, 2403-2414 (2018).

\section{Acknowledgements}

The authors would like to thank the patients participating in this study.

\section{Author contributions}

All authors were involved in drafting the article or revising it critically for important intellectual content, and all authors approved the final version to be published. S.S.A., G.T. and S.A.M.U. had full access to all of the data in the study and take responsibility for the integrity of the data and the accuracy of the data analysis.

\section{Competing interests}

The authors declare no competing interests.

\section{Additional information}

Correspondence and requests for materials should be addressed to S.A.M.U.

Reprints and permissions information is available at www.nature.com/reprints.

Publisher's note Springer Nature remains neutral with regard to jurisdictional claims in published maps and institutional affiliations.

(c) (i)

Open Access This article is licensed under a Creative Commons Attribution 4.0 International License, which permits use, sharing, adaptation, distribution and reproduction in any medium or format, as long as you give appropriate credit to the original author(s) and the source, provide a link to the Creative Commons licence, and indicate if changes were made. The images or other third party material in this article are included in the article's Creative Commons licence, unless indicated otherwise in a credit line to the material. If material is not included in the article's Creative Commons licence and your intended use is not permitted by statutory regulation or exceeds the permitted use, you will need to obtain permission directly from the copyright holder. To view a copy of this licence, visit http://creativecommons.org/licenses/by/4.0/.

(C) The Author(s) 2021 